\title{
Novel Use of Pectin as a Microneedle Base
}

\author{
Yusuf Kemal Demir*; and Oya Kerimoglu \\ Department of Pharmaceutical Technology, Faculty of Pharmacy, Marmara University; Uskudar, Istanbul 34668, \\ Turkey. \\ Received November 4, 2014; accepted January 28, 2015
}

Hydrocolloid pectin formulation was utilized as a novel base for fabricating biodegradable micro-needle (MN) arrays. The pectin MNs were, on average, found to be $897.71 \pm 3.48 \mu \mathrm{m}$ in height and $234.31 \pm 2.27 \mu \mathrm{m}$ in base width, with an inter base spacing of $498.66 \pm 1.60 \mu \mathrm{m}$, and corresponding to an aspect ratio of $3.83 \pm 0.04$. Bovine serum albumin (BSA) and pectin gel interaction was found to be dependent on the loaded protein amount. By contrast, regardless of the amount of BSA incorporated, pectin MNs competed with BSA to form a complex with $\mathrm{Cu}^{2+}$ ions in a bicinchoninic acid (BCA) kit. The glass transition of the pectin MN base was found to be $145.15 \pm 12.09$, with a delta $\mathrm{Cp}$ of $2.60 \pm 0.02 \mathrm{Jg}^{-1} \mathrm{~K}^{-1}$. Because pectin MNs are skin friendly and naturally occurring, with biodegradable and hydrocolloidal features, they are promising vehicle for the controlled release of macromolecules.

Key words microneedle; pectin; transdermal; drug delivery; hydrocolloid

Inspiration from the silicon microchip led scientists to fabricate the first-ever micro-needle arrays (MNs) in 1998, ${ }^{1}$ paving the way for a novel method of transdermal drug delivery, dubbed minimally invasive systems. ${ }^{2)} \mathrm{MNs}$ have the ability to create micro conduits on the skin, enhancing drug transport across the stratum corneum (SC). They are designed long enough to puncture the SC but short enough to prevent nerve stimulation, ${ }^{3)}$ meaning that they are essentially pain-free systems. ${ }^{4,5)}$

Although the first silicon MNs were of being too brittle and possessing non-biocompatible nature, ${ }^{6,7)}$ intensive research since then has yielded many pharmaceutical, polymer-based MN systems as alternatives. ${ }^{2,8-16)}$ Micro manufacturing techniques, ${ }^{17,18)}$ deduction of suitable polymers for MNs and optimization of the formulation parameters to produce MNs that possess characteristics like solubility, swelling, and biodegradability were previously published. ${ }^{8)}$

Polymeric MNs have great potential to start a million dollar market up by revolutionizing not only the drug delivery systems (conventional transdermal patches and hypodermic needles), but also drug monitoring devices (both bench top and portable systems).

Pectin is in the 'generally regarded as safe' (GRAS) list and thus has been used thoroughly in pharmaceutical and food applications. ${ }^{19)}$ This, along with its thickening, gelling, ${ }^{20)}$ emulsifying, ${ }^{21,22)}$ protein-stabilizing ${ }^{23,24)}$ capabilities as well as ease of sourcing make it a promising candidate for many dermal and transdermal formulations. Although there has been much research about using pectin in different drug dosage forms ${ }^{25-30)}$ and delivery systems, ${ }^{31-35)}$ such as transdermal patches, ${ }^{36-38)}$ its use as MN arrays is an unexplored area that requires much more attention.

Here in this study, pectin was used for the first time as a base in solid, out-of-plane MN array fabrication for use in transdermal drug delivery applications that may have a great impact on the market.

\footnotetext{
${ }^{\dagger}$ Present address: Faculty of Pharmacy, The University of Sydney; Camperdown, NSW 2006, Australia.
}

\section{Experimental}

Chemicals Genu Pectin (USP/100) was kindly supported from CPKelco (Atlanta, GA, U.S.A.). Apple Pectin, Citrus Pectin were gifted from Herbstreith \& Fox KG Pektin-Fabriken (Neuenbürg/Württ, Germany).

Fabrication of Pectin Microneedle Arrays (MNs) Microfabricated male MNs were glued from their base sides with cyanoacrylate into the three dimensional (3D) printed acrylonitrile butadiene styrene (ABS) plastic mold (Fig. 1a), where polydimethylsiloxane (PDMS) (10:1) was injected with a piston (Fig. 1b) and then followed by sealing of the ABS mold with its lid (Fig. 1c). Figure 1d shows cross sectional view of the PDMS loaded on top of the microneedle template. After that centrifugation at high speed (please follow the rest of the protocol) was applied (Fig. 1e), and kept at $80^{\circ} \mathrm{C}$ for at least $4 \mathrm{~h}$ in order to finalize polymerization of the PDMS and replicate the exact structure of the male master microneedle template. All these steps explain conventional micromolding. Once PDMS finished the curing step, it was peeled from the male master template off, and this time PDMS micromold was used as chamber for preparation of hydrocolloid pectin MNs, and thus inserted inside the 3D printed ABS plastic mold (Fig. 1f).

Half the theoretical amount of pectin is slowly added into an amount of the ultra-pure Milli-Q water being stirred at $80^{\circ} \mathrm{C}$ and subjected to pre-stirring at $1750 \mathrm{rpm}$ for $2 \mathrm{~h} .{ }^{39)}$ At the end of $2 \mathrm{~h}$, the aqueous drug solution is stirred together with the remaining theoretical pectin amount at the same speed for about $2 \mathrm{~h}$ by means of an overhead type stirrer (IKA-overhead Stirrer, Eurostar Power Basic, IKA Labortechnik, Germany) until $7 \%$ by weight of a homogeneous and soft pectin gel is obtained.

Preparation of each pectin MNs, $90 \mathrm{mg}$ of gel with or without active drug is injected into the PDMS micromold (Fig. 1f), and after this polymeric gel loading, ABS plastic was sealed with its lid (Fig. 1g). Then, it is centrifuged at $3500 \mathrm{rpm}$ for $20 \mathrm{~min}$. Instead of centrifugation $-60 \mathrm{cmHg}$ vacuum for $2 \mathrm{~h}$ can also be applied. Pectin MNs obtained after centrifugation is taken out of the micromold by using double sided tape (Fig. 1h), where overall a spin-casting method was mainly 

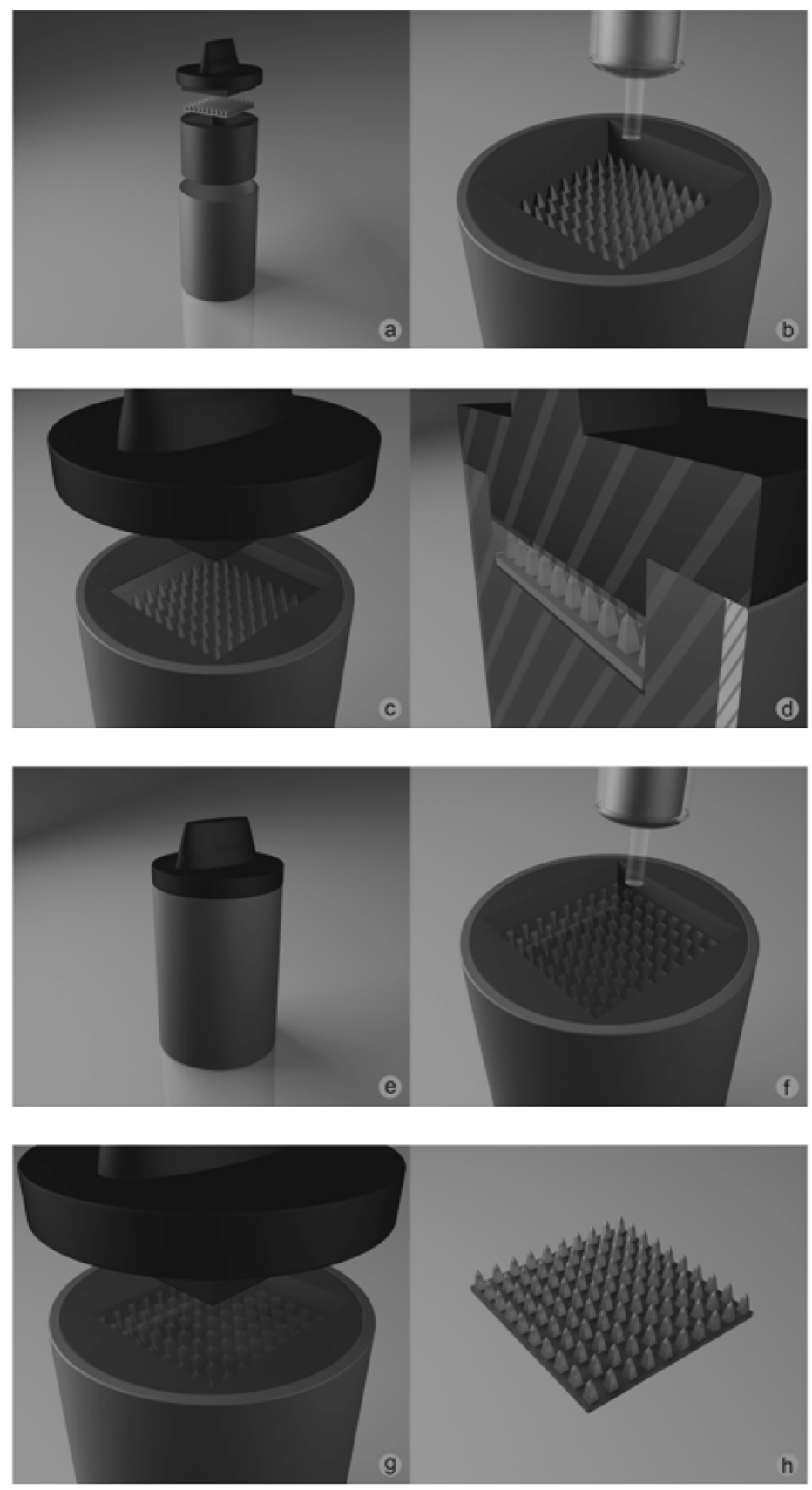

Fig. 1. Microfabrication Steps of Conventional Micromolding, and Pectin Microneedle Arrays

(a) Attachment of male MNs into the ABS mold. (b) Injection of PDMS into (a). (c) Sealing of filled ABS mold with PDMS and male MNs. (d) Cross sectional view of PDMS loaded male MNs. (e) Centrifugation, curing step in oven, and peeling off cured PDMS and male MNs. (f) Microinjection of pectin gel into the cured female PDMS mold. (g) Centrifugation, and curing step at room temperature. (h) Peeling off cured pectin MNs and female PDMS mold.

used. ${ }^{2,17,18)}$

Scanning electron microscopy (SEM) analysis of pectin MNs, differential scanning calorimetry (DSC) analysis of pectin MNs, bovine serum albumin (BSA)/pectin MNs interaction studies with bicinchoninic acid (BCA) method, BSA/ pectin MNs were performed to the similar of our earlier publication. ${ }^{8)}$

\section{Results and Discussion}

Fabrication of Pectin MNs Master MNs templates can be fabricated by any micro manufacturing technique. Polymeric materials, such as pectin, can give exact replicas of the male needles. In the conducted experiments, high methoxyl pectin
(HMP) and low methoxyl pectin (LMP) or amidated pectin is preferred to manufacture biodegradable MNs, due to their gelation characteristics. In order to facilitate gelation, excipients such as sugar, sugar syrup, etc. can be used. Pectin MNs with a needle shaft height $897.71 \pm 3.48 \mu \mathrm{m}$, needle base diameter $234.31 \pm 2.27 \mu \mathrm{m}$, interneedle base spacing of $498.66 \pm 1.60 \mu \mathrm{m}$ yielding an aspect ratio of $3.83 \pm 0.03$ were fabricated (Table 1, Fig. 2).

SEM and DSC Analysis of Pectin MNs An environmental scanning electron microscope (ESEM) was used ${ }^{8)}$ for structural analysis of pectin MNs. SEM images of pectin MNs (Figs. 3a, b) were reproducible and smooth. Even needle tips and bases were very clear, rigid, and have a good accordance 
Table 1. Physical Characteristics of 7\% w/w Pectin USP/100 MN Arrays Prepared from PDMS Micromolds (Means \pm S.D., $n=36$ )

\begin{tabular}{cccc}
\hline \hline Mold No. & Needle shaft height $(\mu \mathrm{m})$ & Needle base diameter $(\mu \mathrm{m})$ & Interneedle base spacing $(\mu \mathrm{m})$ \\
\hline 1 & $901.60 \pm 2.57$ & $234.61 \pm 1.38$ & $499.00 \pm 1.20$ \\
2 & $893.71 \pm 6.29$ & $234.20 \pm 2.22$ & $498.68 \pm 1.03$ \\
3 & $893.42 \pm 3.33$ & $234.33 \pm 2.52$ & $498.61 \pm 1.43$ \\
4 & $901.60 \pm 2.57$ & $234.61 \pm 1.38$ & $499.00 \pm 1.20$ \\
5 & $898.11 \pm 2.94$ & $234.65 \pm 1.90$ & $498.23 \pm 3.54$ \\
6 & $897.86 \pm 3.20$ & $233.48 \pm 4.22$ & $3.81 \pm 0.04$ \\
\end{tabular}

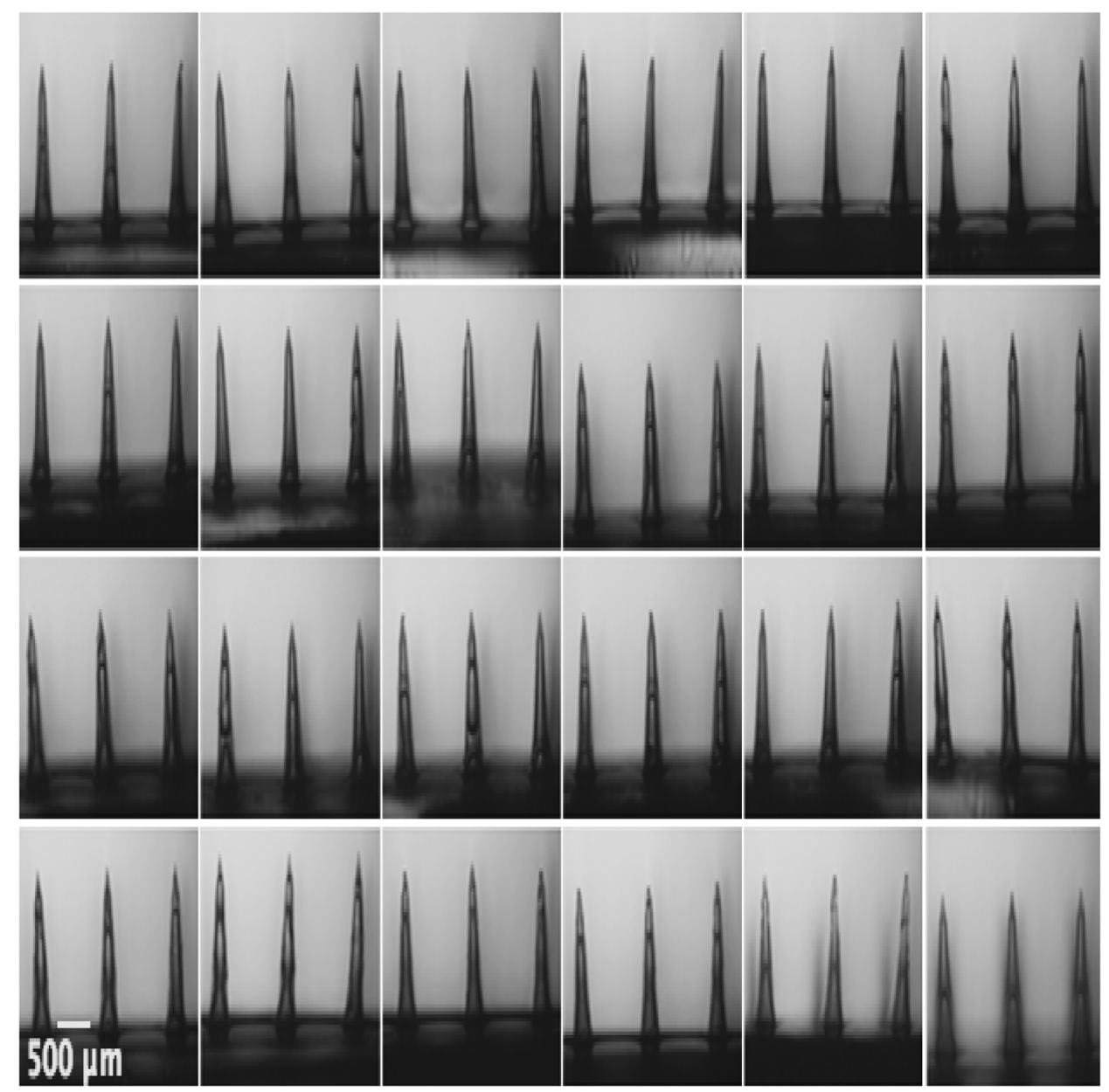

Fig. 2. Digital Photographs of Sections from $10 \times 10$ Biodegradable Pectin MNs

with male templates that were originally reproduced from. The sharpness of needle tips and non waive structure of array base not only shows the perfectness of the curing step but also convenience of the pectin biomaterial as microneedle base.

Hardy/glassy to soft/rubber transition of pectin microneedle bases were studied with DSC system (Netzsch 204 F1 Phoenix ${ }^{\circledR}$; Gerätebau GmbH, Wittelsbacherstrabe, Bavaria, Germany) of our earlier published protocol. ${ }^{8)}$ At $44.7^{\circ} \mathrm{C}$, an exothermic peak was observed representing the crystallization. At around $214.1^{\circ} \mathrm{C}$ a melting was observed followed by another recrystallization peak approximately at $240^{\circ} \mathrm{C}$. The glass transition $\left(T_{\mathrm{g}} \mathrm{mid}\right)$ of pectin MN base was $145.15 \pm 12.09$, with a delta $\mathrm{Cp}$ of $2.60 \pm 0.02 \mathrm{~J} \mathrm{~g}^{-1} \mathrm{~K}^{-1}$.

BSA/Pectin MNs Interaction Studies Using BCA Method Consequences of interaction studies among fabricated pectin devices (pectin microneedle and pectin gels) and BSA solution were examined using BCA kit according to our earlier published procedure. ${ }^{2)}$ Protein (BSA) amount of both the theoretical concentrations were kept constant as $10 \mathrm{mg}$ or $5 \mathrm{mg}$ per device (MNs and gels), and reported in Table 2.

Statistical Analysis Polymer/BSA interaction experiment results were performed with two tailed unpaired $t$ test, where $p<0.05$ was considered to indicate a statistically significant difference. Therefore, a statistical significant difference was observed between the theoretical and practical BSA concentrations as regulated with BCA kit in the presence of polymeric MNs $7 \% \mathrm{w} / \mathrm{w}$ pectin ( $t$-value: 7.57$)$. It is conjectured that pectin polymeric MNs (without depending on the protein loading capacity) illustrated an interfering with BCA working reagent and strive against BSA to assemble a complex with the $\mathrm{Cu}^{2+}$ ions of the BCA kit. On the other hand, 7\% pectin gels with high capacity protein loading (10 $\mathrm{mg}$ in this case) was not a cause of interaction, in other terms delivery amounts of BSA from pectin gels could be quantified with BCA method. 
In general, natural polymers have promising properties such as being non-toxic even with great quantities, cytocompatible, biocompatible, biodegradable and mucoadhesive, e.g., which overall make them as primed biomaterials even in gene delivery carriers and tissue engineering applications. ${ }^{40,41)}$ There is a tremendous need for skin friendly formulations, and since pectin is abundantly found in natural products, such as apple pomace, citrus peel, and sugar beet, e.g., it is found very plausible natural biomaterial here. Pectin is biodegradable, biocompatible, inexpensive, easily castable GRAS biomaterial, thus it is here selected as natural polymer, which then proofed its greatness as microneedle base material.

According to a comprehension of the present invention, in the procedures where pectin polymer was used in the content of the poke and release micro needle, it is proposed that the pectin aqueous solutions and gels comprise pectin of 5 to $10 \%$ (w/v), preferably $7 \%(\mathrm{w} / \mathrm{v})$.

PDMS has unique features that make it very convenient chamber for replicating inert and hydrophilic polymers. ${ }^{8)}$ Six different PDMS micromolds (Table 1, Fig. 1f) were used and since using the same polymer and the fabrication steps, there were not significant differences among the digitally measured microneedles with one-way ANOVA $(p>0.05)$. Practical measurements of the pectin microneedles (Fig. 2) were also very similar to the theoretical dimensions of the male master templates (Fig. 1a).

In this scenario very sensitively microfabricated sharp, pyramidal microneedles were used as template mold. Fabrication precision of pectin MNs for their height was $\pm 0.39 \%$, for the base diameter $\pm 0.97 \%$, and the interbase spacing was $\pm 0.32 \%$ within the targeted dimensions. The fabrication precision and repeatability of pectin MNs was close to the findings of earlier microfabricated poly lactic-co-glycolic acid (PLGA) MNs, and better than sodium alginate (SA), polyvinyl alcohol (PVA)-gelatin, chitosan, and hydroxypropyl cellulose (HPC) type MNs. ${ }^{8}$

According to the findings from structural morphology of the arrays, the surface smoothness and reproducibility of pectin base substrates were as clear and acceptable as its needles where none of them were bended (Figs. 3a, b), and coherent with the male master templates (Fig. 1a).

A sensitive analytical/bio analytical method is crucial for detecting and quantifying of small and macromolecular drugs that are incorporated in polymer matrixes. This method also should be suitable for discriminating the drug from the used matrix without depending to their amounts.

Absorbance values for BSA in the presence and absence of pectin gels, and pectin MNs were statistically compared. When $5.0 \mathrm{mg}$ BSA was incorporated in $7 \% \mathrm{w} / \mathrm{w}$ pectin gels an interaction was observed $(p<0.05)$, whereas blending $10 \mathrm{mg}$ BSA in $7 \% \mathrm{w} / \mathrm{w}$ pectin gels was not lead to any interaction $(p>0.05)$ (Table 2).

On the other hand, regardless of incorporated BSA amount in $7 \% \mathrm{w} / \mathrm{w}$ pectin $\mathrm{MNs}$, a discernible absorbance records were observed. Absorbance values at $562 \mathrm{~nm}$ using BCA kit of even slight amount $(5 \mathrm{mg})$ of BSA was impeded with pectin MNs, where statistical comparisons for both were stated as significant $(p<0.0001)$ (Table 2$)$. The optical density (OD) values for BSA loaded pectin MNs were higher than its gel and solution type formulations (Table 2). These interesting finding for
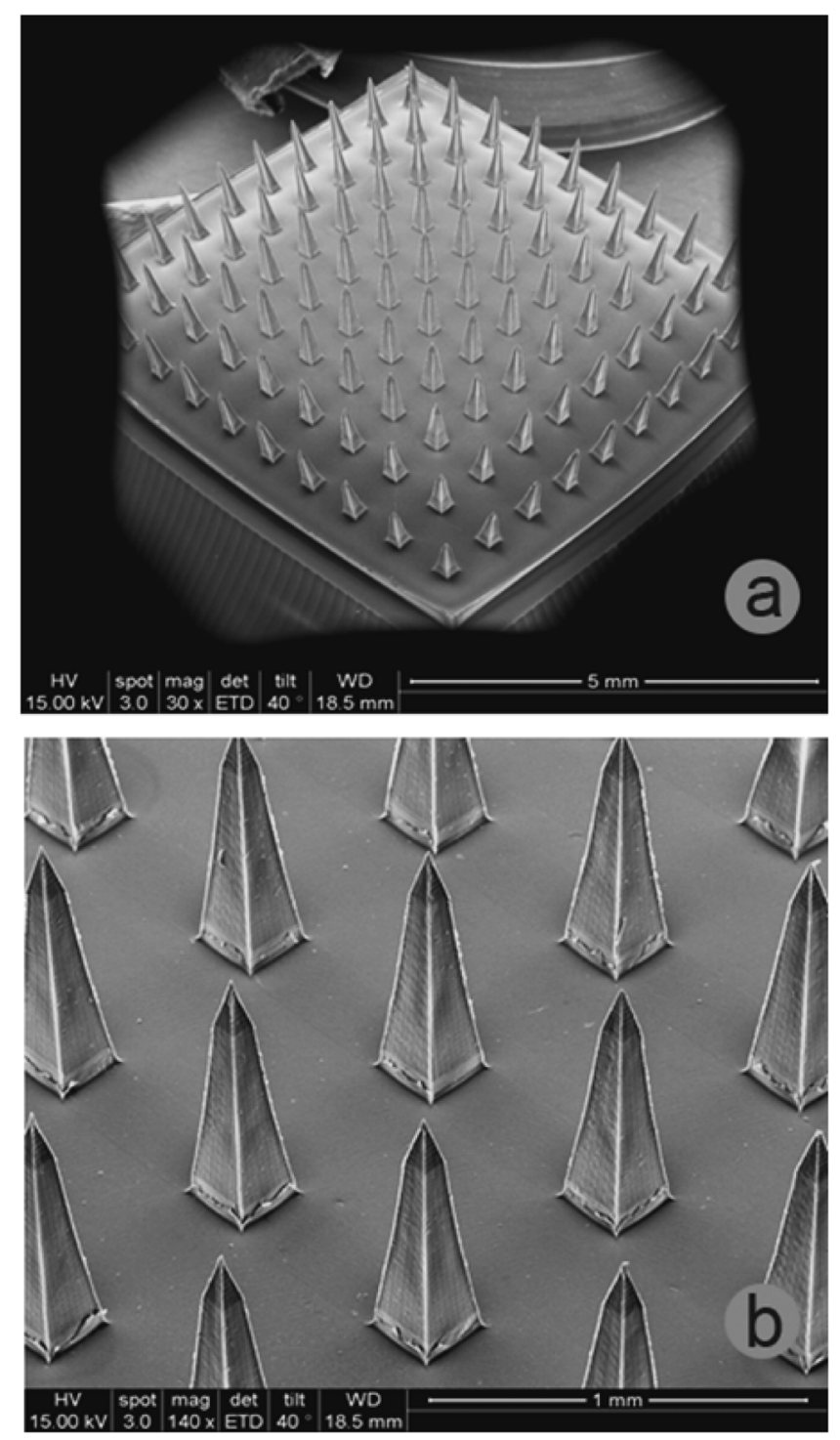

Fig. 3. SEM Photograph of Pectin MNs Fabricated from PDMS Micromould That Were Replication of Male MNs

(a) Whole part of $10 \times 10$ pectin MN array. (b) Parts from $10 \times 10$ pyramidal pectin $\mathrm{MN}$ array.

Table 2. Interaction Studies of BSA against Pectin Gels and MNs Using BCA Method (Means \pm S.E.M., $n=12$ )

\begin{tabular}{|c|c|c|c|c|}
\hline Types of polymeric MNs & $\begin{array}{l}\text { BSA concentration in } \\
\text { the polymers free case }(\mu \mathrm{g} / \mathrm{mL})\end{array}$ & $\begin{array}{l}\text { BSA concentration in } \\
\text { the polymers intact case }(\mu \mathrm{g} / \mathrm{mL})\end{array}$ & $p$-Value & $t, d f$ Value \\
\hline $7 \%$ Pectin gel & $1076.51 \pm 11.42$ & $1084.69 \pm 11.13$ & 0.6130 & $0.5131,22$ \\
\hline $7 \%$ Pectin $\mathrm{MN}$ & $1054.16 \pm 14.19$ & $1691.13 \pm 82.98$ & $<0.0001^{b)}$ & $7.567,22$ \\
\hline $7 \%$ Pectin gel & $568.02 \pm 7.01$ & $542.72 \pm 6.40$ & $0.0141^{a)}$ & $2.67,22$ \\
\hline $7 \%$ Pectin $\mathrm{MN}$ & $540.22 \pm 5.63$ & $713.93 \pm 6.81$ & $<0.0001^{b)}$ & $19.65,22$ \\
\hline
\end{tabular}

$a, b)$ Statistically different. 
pectin MNs might be due to their degradable, or hydrocolloid polymeric structure, where they require more medium to be dissolved or more exposure time for the erosion in dissolving medium (phosphate buffered solution $7.4 \mathrm{pH}$ ) than the gels demand. The reason of pectin gels that was not causing any interference with the BSA might be already owing high water content in its structure, which MNs have not possess, and evaporated during the drying/curing step.

The spectrum curves of $10 \mathrm{mg}$, and $5 \mathrm{mg}$ BSA loaded in $7 \% \mathrm{w} / \mathrm{w}$ pectin MNs were measured with BCA kit. The overlapped spectrum curve of pectin MNs and BSA solutions were also considered distinguishable (figures are not shown).

Our group reported before a complexion with the $\mathrm{Cu}^{2+}$ ions of the BCA kit and the polymeric MNs, but SA MNs was not interacted with BCA kit reagents. ${ }^{2)}$ In this study, it is conjectured that pectin gels but not its MNs also did not interfere with the kit reagents

\section{Conclusion}

Manufacturability, repeatability, and accuracy parameters of for the first time formulated solid, out-of-plane pectin MNs were found convenient, where its replication precision was $\pm 0.39 \%$ for the needle height, base diameter was $\pm 0.97 \%$, and for the interbase spacing was $\pm 0.32 \%$ within the desired dimensions. Having Tg value over room temperature enhances pectin possibility as microneedle base. BCA colorimetric method is found convenient analytical method for BSA protein analysis loaded in pectin gel. Due to being skin friendly and naturally endowed, and having biodegradable, hydrocolloid features, pectin MNs could be a promising device for the release of macromolecules.

Funding Sources The authors declare that there is no support of funding to report.

Acknowledgments Authors gratefully acknowledge assistance supported by Bilkent University Mechanical Engineering Department and UNAM-Institute of Materials Science and Nanotechnology. Authors thank to CPKelco (Atlanta, GA, U.S.A.), Prof. Dr. Hans-Ulrich and Endress Herbstreith \& Fox KG Pektin-Fabriken (Neuenbürg/Württ, Germany) for kindly gifting the pectin. Authors would like to thank Ziya Sahin for proofreading and corrections.

Conflict of Interest The authors declare no conflict of interest. Yusuf Kemal Demir is pursuing a patent TR Patent 201209058 A2.

\section{References}

1) Henry S., McAllister D. V., Allen M. G., Prausnitz M. R., J. Pharm. Sci., 87, 922-925 (1998).

2) Demir Y. K., Akan Z., Kerimoglu O., PLoS ONE, 8, e63819 (2013).

3) Kaushik D., Kilfoyle B., Thakur R., Michniak-Kohn B. B., "Handbook of Non-invasive Drug Delivery Systems," ed. by Kulkarni V. S., Elsevier Inc., MA, U.S.A., 2010, pp. 135-164.

4) Haq M. I., Smith E., John D. N., Kalavala M., Edwards C., Anstey A., Morrissey A., Birchall J. C., Biomed. Microdevices, 11, 35-47 (2009).

5) Coulman S., Allender C., Birchall J., Crit. Rev. Ther. Drug Carrier Syst., 23, 205-258 (2006).

6) Wilke N., Hibert C., O'Brien J., Morrissey A., Sens. Actuators A: Phys., 123-124, 319-325 (2005).
7) Griss P., Tolvanen-Laakso H. K., Merilainen P., Stemme G., IEEE Trans. Biomed. Eng., 49, 597-604 (2002).

8) Demir Y. K., Akan Z., Kerimoglu O., PLoS ONE, 8, e77289 (2013).

9) Demir Y. K., "Polymeric microneedle arrays for transdermal drug delivery," Ph.D. thesis, Institute of Health Sciences, Marmara University (2012)

10) Chaudhri B. P., Ceyssens F., Neves H. P., La Manna A., Van Hoof C., Puers R., Conf. Proc. IEEE Eng. Med. Biol. Soc., 2011, 36803683 (2011).

11) Donnelly R. F., Majithiya R., Singh T. R., Morrow D. I., Garland M. J., Demir Y. K., Migalska K., Ryan E., Gillen D., Scott C. J., Woolfson A. D., Pharm. Res., 28, 41-57 (2011).

12) Chu L. Y., Choi S. O., Prausnitz M. R., J. Pharm. Sci., 99, 4228 4238 (2010).

13) Sullivan S. P., Koutsonanos D. G., Del Pilar Martin M., Lee J. W., Zarnitsyn V., Choi S. O., Murthy N., Compans R. W., Skountzou I., Prausnitz M. R., Nat. Med., 16, 915-920 (2010).

14) Aoyagi S., Izumi H., Fukuda M., Sens. Actuators A: Phys., 143, 20-28 (2008).

15) Ito Y., Yoshimitsu J., Shiroyama K., Sugioka N., Takada K., J. Drug Target., 14, 255-261 (2006).

16) Kochhar J. S., Lim W. X., Zou S., Foo W. Y., Pan J., Kang L., Mol. Pharm., 10, 4272-4280 (2013).

17) Falo J. R. L. D., Erdos G., Ozdoganlar O. B., Patent No. US 2011/0098651 A1, U.S.A. (2011).

18) Bediz B., Korkmaz E., Khilwani R., Donahue C., Erdos G., Falo L. D. Jr., Ozdoganlar O. B., Pharm. Res., 31, 117-135 (2014).

19) Morris G., Kok S., Harding S., Adams G., Biotechnol. Genet. Eng. Rev., 27, 257-284 (2010).

20) Imeson A., "Thickening and Gelling Agents for Food," Aspen Publishers, Inc., Second Ed., U.S.A., 1997.

21) Vollrath M. K. P. D., Bilek H. M., Burapapadh K. M., Dogangüzel M. M., Forschungsberich Beuth Hochschule für Technik Berlin, 43-47 (2009).

22) Akhtar M., Dickinson E., Mazoyer J., Langendorff V., Food Hydrocoll., 16, 249-256 (2002).

23) Xiaolin H., Patent No. EP1338210, U.S.A., 2009.

24) Gerrish T. C., Patent No. US6221419 B1, U.S.A., 2001.

25) Sriamornsak P., Int. J. Pharm., 169, 213-220 (1998).

26) Kim H., Fassihi R., J. Pharm. Sci., 86, 316-322 (1997)

27) Munjeri O., Collett J. H., Fell J. T., J. Controlled Release, 46, 273-278 (1997).

28) Ashford M., Fell J., Attwood D., Sharma H., Woodhead P., J. Controlled Release, 30, 225-232 (1994).

29) Liu L., Fishman M. L., Kost N. J., Hicks K. B., Biomaterials, 24, 3333-3343 (2003).

30) Wakerly Z., Fell J. T., Attwood D., Parkins D. A., Int. J. Pharm. 129, 73-77 (1996).

31) Waleh H., Springer S., Patent No. 2491537, U.S.A., 1949

32) Valenta C., Adv. Drug Deliv. Rev., 57, 1692-1712 (2005).

33) Baloğlu E., Ozyazici M., Yaprak Hizarcioglu S., Senyigit T., Ozyurt D., Pekcetin C., Pharm. Dev. Technol., 11, 477-484 (2006).

34) Liu L., Chen G., Fishman M. L., Hicks K. B., Drug Deliv., 12, 149-157 (2005).

35) Cliento R. D., Freeman F. M., Patent No. 4773409, U.S.A., 1988.

36) Güngör S., Bektaş A., Alp F. İ., Uydeş-Doğan B. S., Özdemir O., Araman A., Özsoy Y., Pharm. Dev. Technol., 13, 283-289 (2008).

37) Attia D. A., Aust. J. Basic Appl. Sci., 3, 2154-2165 (2009).

38) Musabayane C. T., Munjeri O., Matavire T. P., Ren. Fail., 25, 525534 (2003).

39) "Production methods of jamms, jellies and marmalades.": ‘http://www. herbstreith-fox.de/fileadmin/tmpl/pdf/broschueren/Konfituere englisch.pdf), cited September 02, 2013.

40) Ratner B. D., Bryant S. J., Annu. Rev. Biomed. Eng., 6, 41-75 (2004).

41) Dang J. M., Leong K. W., Adv. Drug Deliv. Rev., 58, 487-499 (2006). 